\title{
A THREE-DIMENSIONAL PROGRAM FOR THE TREATMENT OF OBESITY*
}

\author{
RICHARD B. STUART $†$ \\ The University of Michigan, Ann Arbor, Michigan, U.S.A.
}

(Received 15 October 1970)

\begin{abstract}
Summary-Obesity is seen as a consequence of a positive balance of energy consumed over energy expended. The reduction of obesity is accordingly sought through the reduction in the amount of food eaten coupled with an increase in the rate at which energy is expended. Both the reduction in the rate of eating and the increase in the rate of exercise are sought through management of critical aspects of the environment. Specific recommendations are made for the behavioral treatment of obesity, with the success of the treatment seeming to depend upon the effectiveness with which environmental stimuli are brought under control rather than depending upon motivational or other personal characteristics of the overeater. Pre-test data generated by the use of this procedure, coupled with the results of several recent studies appear to indicate uniquely positive results for the behavioral control of overeating.
\end{abstract}

W HETHER overweight is determined by gross body weight (Metropolitan Life Insurance Company, 1969) or skin-fold measurement (Seltzer and Mayer, 1965) even when differences in fat as a proportion of body weight are controlled (Durnin and Passmore, undated, p. 137), at least one in five Americans is found to be overweight (United States Public Health Service, undated). The social and economic costs of being overwieght are staggering and are complicated by greatly increased vulnerability to a broad range of physical diseases, including cardiovascular and renal diseases, maturity-onset diabetes, cirrhosis of the liver, and gall bladder diseases, among many others (Mayer, 1968) + Despite the history of concern with obesity and the magnitude of the problem, little uncontested knowledge has been accumulated with respect to its etiology and treatment. Mayer (1968) has suggested that genetic factors may contribute to the onset of a small number of cases, while an additional small number of cases can be explained on the basis of injury to the hypothalamus, hormonal imbalance and other threats to normal metabolism. The exact role of genetic and physiological factors has, however, remained a mystery, and there has been little evidence to countermand an early observation by Newburgh and Johnston (1930) that most cases of obesity are:

* Portions of this paper were presented at the annual meeting of the American Bariatrics Society, Washington, D.C., November 1969, and at the Fourth Annual Meeting of the Association for the Advancement of Behavior Therapy, Miami, Florida, 6 September, 1970. The author wishes to express his gratitude to Barbara Davis, Judith Braver and Merrilee Oakes who contributed significantly to the development and testing of the approach which is described, and to Lynn Nilles for editorial assistance in the preparation of this manuscript. A more detailed description of the procedures may be found elsewhere (Stuart and Davis, in press).

† Requests for reprints should be sent to Richard B. Stuart, School of Social Work, University of Michigan, 1065 Frieze Building, Ann Arbor, Michigan 48104.

+ It has been argued that the relationship between obesity and such illnesses as cardiovascular diseases depends in part on the way in which fat is accumulated. For example, "People who become fat on a high carbohydrate, low fat diet are much less prone to develop atherosclerotic and thrombotic complications than thosc on a high fat diet (Cornell Conferences on Therapy, 1958, p. 87)." 
. . never directly caused by abnormal metabolism but (are) always due to food habits not adjusted to the metabolic requirement - either the ingestion of more food than is normally needed or the failure to reduce the intake in response to a lowered requirement (p. 212).

Therefore most obesities can be attributed to an excess of food intake beyond the demands of energy expenditure, and a major objective in treating obesity is a reduction in the amount of excess food consumed.

Just as there is uncertainty concerning the etiology of obesity, there is great confusion over the role of psychological factors in overeating and its management. Some authors have contributed various useful typologies; for example, Stunkard (1959a) classified eating patterns as night eating, binge eating and eating without satiation, while Hamburger (1951) classified the triggers of excessive eating as either external or intrapsychic. Despite Suczek's (1957) observation that "single psychologic factors may not relate to either degree of obesity or ability to lose weight (p. 201)," other authors have sought to identify specific psychological mechanisms associated with obesity. For example, Conrad (1954) postulates that specific intrapsychic factors, such as efforts to prevent loss of love and to express hostility or efforts to symbolically undergo pregnancy and to ward off sexual temptations, underlie obesity. In a similar vein, while eating has been seen as a means of warding off anxiety (Kaplan and Kaplan, 1957), it has also been seen as a depressive equivalent (Simon, 1963). Furthermore. while writers have suggested that "depression, psychosis . . suicide (Cappon, 1958, p. 573)" and other stress reactions have accompanied weight loss (Cornell Conferences on Therapy, 1958; Glucksman et al., 1968), other studies have shown that : (a) the so-called "depression" associated with weight loss by some people is actually just a function of lowered energy due to reduced food consumption (Bray, 1969); (b) negative psychological reactions are frequently not found (Cauffman and Pauley, 1961; Mees and Keutzer, 1967); and (c) a reduction in anxiety and depression may actually accompany weight loss (Shipman and Plesset. 1963). Despite this evidence, Bruch's (1954) admonition that treatment of overeating which does not give "psychologic factors ... due consideration (can lead) at best to a temporary weight reduction (while being) considered dangerous from the point of view of mental health (p. 49)" is still influential in dissuading experimenters and therapists from undertaking parsimonious treatment of overeating.

While the research pertaining to physiological and psychological concomitants of obesity has led to some paradoxical conclusions, Stunkard's (1968) review of environmental factors related to obesity has demonstrated a clear-cut connection between obesity and socioeconomic status, social mobility and ethnic variables. It is interesting to note, however, that where comparative data are available, the differences ascribed to each of these factors are stronger for women than men. One explanation of this sex difference may be that the physical expenditure of energy in work may reduce the tendency toward adiposity of lower class, socially nonmobile men while the women, faced with relative inactivity, may show a more direct effect of high carbohydrate, low protein diets common at lower socioeconomic strata (Select Committee on Nutrition and Human Needs, 1970).

The literature describing the treatment of obesity is dismal and confusing. One authoritative group noted:

... most obese patients will not remain in treatment. Of those who do remain in treatment, most will not lose significant poundage, and of those who do lose weight, most will regain it promptly. In a careful follow-up study only 8 per cent of obese patients 
seen in a nutrition clinic actually maintained a satisfactory weight loss (Cornell Conferences on Therapy, 1958, p. 87).

Failure has been reported following some of the most ambitious and sophisticated treatments (e.g. Mayer, 1968, pp. 1-2; Stunkard and McLaren-Hume, 1959), while success has been claimed for some of the more superficial "diet-clinic"-type approaches (e.g. Franklin and Rynearson, 1960). The role of drugs has been extolled by many writers, while others have cautioned that their side effects strongly contraindicate their use (American Academy of Pediatrics, 1967; Gordon, 1969; Modell, 1960). Fasting has been shown to have a profound effect upon weight loss (e.g. Bortz, 1969; Stokes, 1969), but the results have been shown to be short-lived as the patient is likely to quickly regain lost weight when he leaves the hospital setting (MacCuish et al., 1968). Claims of success have also been advanced for individual and group psychotherapy (e.g. Kornhaber, 1968; Mees and Keutzer, 1967; Stanley et al., 1970; Stunkard et al., 1970; Wagonfield and Wolowitz, 1968) and hypnosis (Hanley, 1967; Kroger, 1970), although these reports are typically not supported by controlled investigation. Finally, positive outcomes have been reported for behavior therapy techniques ranging from token reinforcement (Bernard, 1968), aversion therapy (Mayer and Crisp, 1964) and covert sensitization (Cautela, 1967) through complex contingency management procedures. Illustrative of the latter approaches are the work of Stuart (1967), which has been replicated in controlled studies by Ramsay (1968) and Penick and his associates (Penick et al., 1970), and the work of Harris (1969), which included control-group comparisons in the original research.

It is probably true that behavior therapy has offered greater promise of positive results than any other type of treatment. This paper will present a rationale of and description for the treatment of overeating based upon behavioral principles.

\section{RATIONALE}

The treatment of obesity has typically attempted to stress the development of "selfcontrol" by the overeater whose self-control deficit is often regarded as a personal fault. Conceding that behavior modifiers recognize first that self-control is merely the emission of one set of responses designed to alter the probability of occurrence of another set of responses (Bijou and Baer, 1961, p. 81; Ferster, 1965, p. 21 ; Holland and Skinner, 1961, Chapter 47; Homme, 1965, p. 504), and second, that self-controlling responses are acquired through social learning (e.g. Bandura and Kupers, 1964; Kanfer and Marston, 1963), most behaviorists still appear to regard self-control as a personal virtue and its absence a personal deficit (Stuart, 1971). For example, Cautela $(1969$, p. 324) is concerned with the individual's ability to manipulate the contingencies of his own behavior while Kanfer (1971) offers among other explanations for the breakdown of self-control "the patient's commitment to change," a presumed index of the patient's degree of motivation, or "the patient's prior skill in use of self-reward or self-punishment responses for changing behavior," a presumed index of the patient's capacity to utilize treatment.

In any event, the relevance of the concept of self-control to the management of overeating may be questioned in the light of many recent studies. The most basic of these is the work of Stunkard (1959b) who demonstrated that in comparison with nonobese subjects, obese subjects are far less likely to report hunger in association with "gastric motility." Thus the cues for hunger experiences of the obese may be tied to external events. Several 
ingenious studies have contributed to this possibility. First. Schacter and his associates demonstrated that obese subjects are less influenced than nonobese subjects by manipulated fear and deprivation of food (Schacter et al., 1968). while they are more influenced by the time they think it is than by the actual time (Schacter and Gross, 1968). In addition it was shown that when the cues of eating are absent, as on religious fast days, obese subjects are more likely to observe dietary restrictions than nonobese subjects (Schacter, 1968). In a similar vein, Nisbett (1968) and Hashim and Van Itallie (1965) showed that obese subjects are more influenced by the taste of food than are nonobese subjects when the duration of food deprivation is controlled. These varied studies and others suggested that the first of two requirements for the treatment of overeating must stress environmental management rather than self-control because the cues of overeating are environmental rather than intrapersonal.

The second requirement for the management of obesity must be a manipulation of the energy balance-the balance between the consumption of energy as food and the expenditure of energy through exercise. If all of the energy which is derived from the consumed food is expended in exercise, then gross body weight will remain constant. Any excess of food energy consumption over energy expenditure, however, is stored as adiposity at the rate of approximately one pound of body fat for each excessive $3500 \mathrm{kcal}$ (Gordon, 1969, p. 148; Mayer, 1968, p. 158). Weight can therefore be lost through: (1) an increase in the amount of exercise, holding food intake constant; (2) a decrease in the amount of food intake, holding exercise constant; or (3) both an increase in exercise and a decrease in food intake.

It has been well-demonstrated that the rising problem of obesity is associated with decreasing demands for exercise. Mayer (1968) suggested that "inactivity is the most important factor explaining the frequency of 'creeping' overweight in modern societies (p. 821)," while Durnin and Passmore (undated, p. 143) revealed that food intake is typically not adjusted to reduced exercise. Recent evidence adduced by the Agricultural Research Service (1969, pp. 22-24) demonstrated that the diets of young men in higher-income brackets include 20 per cent more kcal than the diets of those with smaller incomes and presumably more physically taxing occupations, and this is most likely to result in some measure of obesity among middle-class males. Increase in the rate of exercise can, however, have a profound effect upon body weight although the amount of exercise necessary is greater than generally expected.* Furthermore, given the fact that an obese person actually expends less energy than a nonobese person doing the same amount of work (e.g. a 250pound man walking $1.5 \mathrm{mph}$ expends $5.34 \mathrm{kcal}$ per min, while a 150 -pound man walking at the same rate and carrying a 100-pound load expends $5.75 \mathrm{kcal}$ per min [Bloom and Eidex, 1967, p. 687]), planned programs for exercise are particularly important. In addition to aiding in the management of gross body weight, exercise programs for the thin as well as the obese seem definitely to reduce the risk of certain cardiovascular diseases (Mayer, 1967).

Just as it is important systematically to increase the amount of exercise, so too is it important to reduce the amount of food or change the nature of foods eaten. Mayer (1968) recommends:

* Stuart (unpublished data) asked a group of obese women to estimate the amount of exercise required to work off the weight gain attributable to such common foods as donuts, ice cream sodas and potato chips. Comparing their answers with the estimates based upon Konishi's (1965) figures for a 150-pound man walking at the rate of 3.5 miles per hr $(29,49$ and 21 min respectively), they were found to underestimate the true work required by from 200 to 300 per cent. 
A balanced diet, containing no less than 14 per cent of protein, no more than 30 per cent of fat (with saturated fats cut down), and the rest carbohydrates (with sucroseordinary sugar-cut down to a low level) ... (p. 160).

Apart from its nutritional advantages, it is important to include a substantial amount of protein in the diet because smaller amounts of protein as opposed to carbohydrates produce satiety and because a portion of the caloric content of protein is used in its own metabolism (Gordon, 1969, p. 149), leaving a smaller proportion as a possible contributor to adiposity. Conversely, it is important to reduce the amount of carbohydrates consumed because a higher proportion of its caloric content is available for adiposity, because at least certain carbohydrates-e.g. sucrose (Yudkin, 1969)-are associated with increased incidence of certain cardiovascular diseases to which obese persons are vulnerable, and because "carbohydrate food causes the storage of unusually large amounts of water (Gordon, 1969, p. 148)" - typically a special problem faced by obese individuals.

The foregoing observations lead to several basic considerations for weight reduction programs. First, it is essential to design an environment in which food-relevant cues are conducive to the maximal practice of prudent eating habits. This is required by the fact that overeating among obese persons appears to be under environmental control. Also, training the patient in the techniques of environmental control will probably reduce the gradual loss of therapeutic effect found in certain (e.g. Silverstone and Solomon, 1965) but not all (Penick et al., 1970) other programs. Second, it is essential to plan toward a negative energy balance. In doing this, however, it is essential to avoid exercise or dietary excesses. They are unlikely to be followed, and if they are followed each may result in iatrogenic complications. Excessive exercise might lead to overexertion or serious cardiovascular illness. Unbalanced diets might lead to physiological disease, while insufficient diets might lead to enervation and physiologically produced depression. It is therefore essential to plan gradual weight-loss programs associated with progressive changes in the energy balance, as these are both safer and more likely to meet with success (Wang and Sandoval, 1969, p. 220). The exact determination of these levels must be empirically determined for each patient, beginning with tables of recommended dietary allowance (e.g. Mayer, 1968, pp. 168-169), adjusting these for the amount of exercise, carefully monitoring weight and mood changes as time on the program progresses, and being careful to make certain that the degree of weight loss provides sufficient motivation for the patient to continue using the program.

\section{TREATMENT}

Translation of the above rationale into a set of specific treatment procedures sometimes requires an arbitrary selection of intervention alternatives derived from contrary or contradictory conclusions in the basic research literature. For example, while Gordon, (1969) repudiated his earlier contention that a patient's eating several smaller meals each day would necessarily result in greater weight loss than his eating only the three traditional meals, others (e.g. Debry et al., 1968) have shown that with caloric intake held constant patients who eat three meals daily may not only maintain their weight but may actually gain weight, while the same patients dividing their caloric allowance into seven meals lose weight precipitously. As another example, Nisbett and Kanouse (1969) demonstrated that obese food shoppers actually buy less the more deprived of food they are while nonobese shoppers increase their food buying as a function of the extent of food deprivation. In contrast, Stuart (unpublished data) demonstrated that when a group of obese women confined their food shopping to the hours of 3:30-5:00 p.m., they purchased 20 per cent more food than when they postponed 
their food shopping until 6:30-8:00 p.m. Thus the therapist reading the Gordon and Nisbett studies would have his patients eat three meals and delay their food shopping until they were at least moderately deprived of food, while the therapist familiar with the work of Debry et al. and Stuart would do just the reverse. The therapist familiar with both must decide which recommendations to follow, framing his decision as a reversible hypothesis which can be invalidated in response to patient-produced data.

The treatment procedures which have been used in this investigation fall into three broad categories. First, an effort is made to establish firm control over the eating environment. This requires: (a) the elimination or suppression of cues associated with problematic eating while strengthening the cucs associated with desirable eating patterns; (b) planned manipulation of the actual response of eating to accelerate desirable elements of the response while decelerating undesirable aspects; and (c) the manipulation of the contingencies associated with problematic and desirable eating patterns. A sample of the procedures used in the service of each of these objectives is presented in Table 1.

TAble 1. Sample Procedures used to Strenghthen appropriate eating; AND TO WFAKFN INAPPROPRIATE EATING

Cue elimination

1. Eat in one room only

2. Do nothing while eating

3. Make available proper foods only: (a) shop from a list; (b) shop only after full meal

4. Clear dishes directly into garbage

5. Allow children to take own sweets
Cue suppression

1. Have company while eating

2. Prepare and serve small quantities only

3. Eat slowly

4. Save one item from meal eat later

5. If high-calorie foods are eaten, they must require preparation

Reduced strength of undesirable responses

1. Swallow food already in mouth before adding more

2. Eat with utensils

3. Drink as little as possible during meals

Provide decelerating consequences

1. Develop means for display of caloric value of food eaten daily, weight changes

2. Arrange to have deviations from program ignored by others except for professionals

3. Arrange to have overeater re-read program when items have not been followed and to write techniques which might have succeeded

\section{Cue strengthening}

1. Keep food, weight chart

2. Use food exchange diet

3. Allow extra money for proper foods

4. Experiment with attractive preparation of diet foods

5. Keep available pictures of desired clothes, list of desirable activities

$$
\begin{gathered}
\text { Increase strength } \\
\text { of desirable responses }
\end{gathered}
$$

1. Introduce planned delays during meal

2. Chew food slowly, thoroughly

3. Concentrate on what is being eaten

$\frac{3 . \text { Concentrate on what is being eaten }}{\downarrow}$

Provide accelerating consequences

1. Develop means for display of caloric value of food eaten daily, weight changes

2. Develop means of providing social feedback for all success by:

(a) family; (b) friends; (c) coworkers; (d) other weight losers; and/or (e) professionals

3. Program material and/or social consequences to follow: (a) the attainment of weight loss subgoals; (b) completion of specific daily behavioral control objectives 
Second, an effort is made to establish a dietary program for each patient on an individual basis. The first step in the development of a diet is completion by the patient of a self-monitoring food intake form. Because patients frequently claim to exist on unbelievably small quantities of food, only to lose weight rapidly when their diet is regulated at amounts two or three times grcater than originally claimed, it is helpful to provide some social monitoring of the use of the monitoring sheets to ensure accuracy. Procedures such as those employed by Powell and Azrin (1968) have proven helpful. When validated eating records have been obtained for a 14-day period, adjustments in food intake can be planned based upon recommended caloric levels, balanced diet planning and adjustments for the level of food intake in light of the patient's exercise. In dietary planning. "food exchange" recommendations are made (Stuart and Davis, 1971) rather than recommendations for specific food choices. In food exchange dieting, foods in each of six food categories (e.g. milk, fruit, meat, etc.) are grouped according to similar caloric levels (e.g. one egg has approximately the same caloric value as one slice of bread). Selections are made according to food exchanges and this greatly increases the ease and precision of meal planning. Furthermore, when this is done as a means of increasing the probability that the diet will be followed, the unavailability of specific foods frequently leads to a termination of the entire dietary program.

Third, an effort is made to develop an individualized aerobics exercise program based upon walking in most cases (Cooper, 1968). In introducing the need for exercise, the patient is offered a choice between adherence to a punishing diet which may lead to chronic discomfort throughout the day and a more permissive diet coupled with exercise which may lead to discomfort for an hour or less per day. When an exercise program is developed, an effort is made to weave the exercise activity into the normal fabric of the patient's day to increase the likelihood that it will be followed. For example, a patient might be asked to park his car 10 blocks from the home of friends he is about to visit, to avoid elevators and walk up to his destinations, and to carry each item upstairs as needed-rather than allowing several items to accumulate-as a means of increasing the number of steps necessary.

\section{RESULTS}

The pilot investigation reported here reflects the treatment of six overweight, married, middle-class women (171-212 pounds) between the ages of 27 and 41. Each woman requested treatment on a self-referred basis. Treatment was offered on an individual basis, but women were randomly assigned to one of two cohorts. Both groups of three patients were asked to complete the Sixteen Personality Factor Questionnaire (Cattell and Eber, 1967) and to keep a 5-week baseline of their weight and food intake. The first group was then offered treatment twice weekly (average 40 min per session) for a 15 -week period, while the second group was asked to practice "self-control" of eating behavior. The self-control subjects were given the same diet planning materials and exercise program that the treatment group was offered. They were not, however, given instruction for the management of food in the environment. At the conclusion of the 15 -week period, the treated group was asked to continue the treatment program and the second group was offered 15 weeks of the same treatment. Approximately 6 months following the termination of treatment of Group 1 and 3 months following the termination of treatment of Group 2, follow-up data were collected including weight, eating patterns and the readministration of the Cattell 16 P.F. The results including follow-up data are presented in Fig. 1. It will be seen that patients in Group 1 lost an average of 35 pounds while those in Group 2 lost an average of 21 pounds. These 
results are consistent with the objective set for gradual weight loss approximating one pound per week. It will also be seen that the mere collection of baseline self-monitoring data was associated with mild weight loss in both groups, although these gains were dissipated as time progressed for the second group. Finally, comparison of the pre- and post-test personality test results reveal little change other than small improvement in "ego stability" and tension (Factors C and Q4) of the 16 P.F.

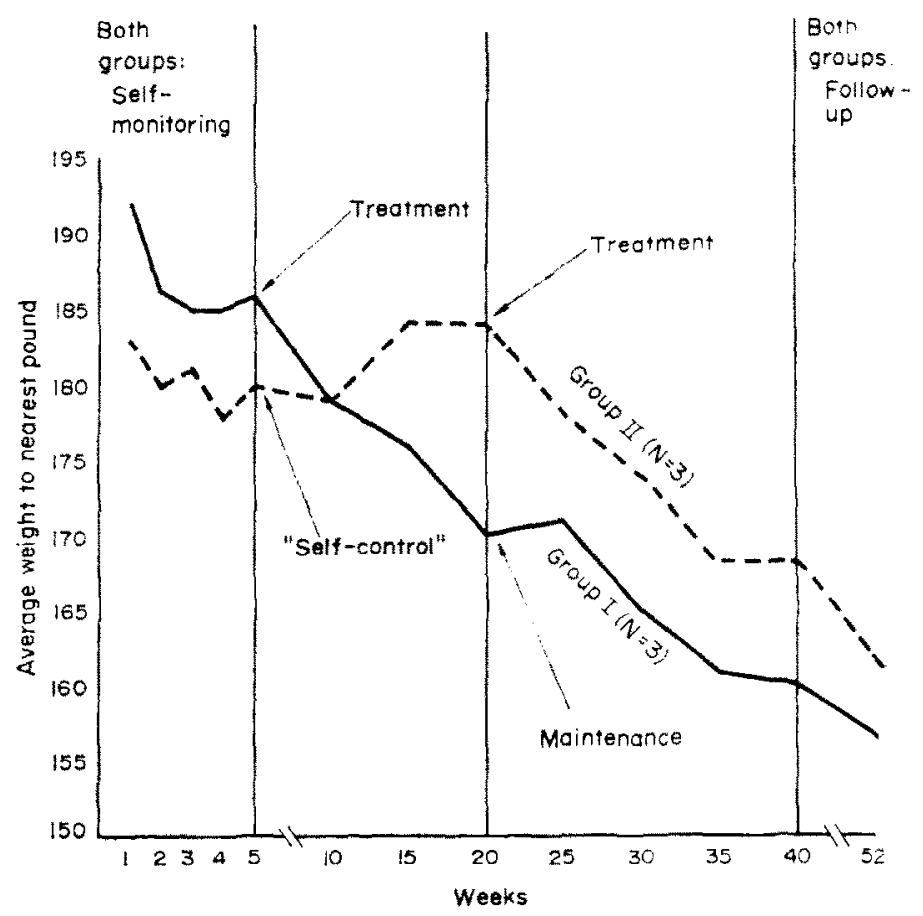

FIG. 1. Weight changes in two groups of women undergoing behavior therapy for overeating.

The results provide suggestive evidence for the usefulness of a threefold treatment of obesity stressing environmental control of overeating, nutritional planning and regulated increase in energy expenditure. The sample size was too small to permit generalization, and the superiority of the initially treated (Group 1) over the initially untreated (Group 2) patients may be due to an inclination among the latter group to be casual about weight reduction. To forestall this possibility, every effort was made to make the treatment appear "official" but no validation of the success of this effort was undertaken. Furthermore, it is perhaps noteworthy that the results were obtained with no evidence of psychological stress in a patient population which was regarded as "well-adjusted" at the start and termination of treatment.

To validate these procedures in any definitive manner, extensive replication is needed using careful experimental control procedures applied to a far more diverse population than was used in this pilot study. Research such as that recently completed by Penick et ai. (1970) has made important strides in this direction. It is only through such experimentation that the vast amount of "faddism and quackery (Gordon ,1969, p. 148)" which characterizes the broad field of obesity comrol can be replaced by a scientifically validated set of procedures. 


\section{REFERENCES}

Agricultural Research Service, U.S. Department of Agricul.ture (1969) Food Intake and Nutritive Value of Diets of Men, Women and Children in the United States, Spring 1965: A Preliminary Report. (ARS 62-18), Washington, D.C.: United States Government Printing Office.

American Academy of Pediatrics, Commrtee on Nutrition (1967) Obesity in childhood. Pediatrics 40, 455-465.

BANDURA A. and KuPERS C. J. (1964) Transmission of patterns of self-reinforcement through modeling. J. abnorm. soc. Psychol. 69, 1-9.

Bernard J. L. (1968) Rapid treatment of gross obesity by operant techniques. Psychol. Rep. 23, 663-666.

BIJOU S. W. and BAER D. M. (1961) Child Development I: A Systematic and Empirical Theory. AppletonCentury-Crofts, New York.

BLonм W. L. and EIDEX M. F. (1967) The comparison of energy expenditure in the obese and lean. Metubolism 16, 685-692.

Bortz W. (1969) A 500 pound weight loss. Am. J. Med. 47, 325-331.

BRAY G. A. (1969) Effect of caloric restriction on energy expenditure in obese patients. Lancet 2, 397-398.

Bruch H. (1954) The psychosomatic aspects of obesity. Am. Practnr Dig. Treat. 5, 48-49.

CAPPON D. (1958) Obesity. Can. Med. Assoc. Jl 79, 568-573.

CATtell R. B. and Eber H. W. (1957) Handbook for the Sixteen Personality Factor Questionnaire. The Institute for Personality and Ability Testing, Champaign, I11.

Cauffman W. J. and Pauley W. G. (1961) Obesity and emotional status. Penn. Med. J/64, 505-507.

Cautela J. R. (1967) Covert sensitization. Psychol. Rep. 20, 459-468.

Cautela J. R. (1969) Behavior therapy and self-control: Techniques and implications. In Behavior Therapy: Appraisal and Status (Ed. C. M. Franks). McGraw-Hill, New York.

Conrad S. W. (1954) The problem of weight reduction in the obese woman. Am. Practnr. Dig. Treat. 5, $38-47$.

COOPER K. H. (1968) Aerobics. Bantam Books, New York.

Cornell Conferences on Therapy (1958) The management of obesity. N. Y. S. J. Med. 58, 79-87.

Debry G., Rohr R., Azouaou G., Vassilitch I. and Mottaz G. (1968) Study of the effect of dividing the daily caloric intake into seven meals on weight loss in obese subjects. Nutritio Dieta 10, 288-296.

Durnin J. V. G. A. and Passmore R. (undated) The relation between the intake and expenditure of energy and body weight. Problemes Actuels D'Endocrinologie et de Nutrition (Serie No. 9), 136-149.

FERSTER C. B. (1965) Classification of behavior pathology. In Research in Behavior Modification (Eds. L Krasner and L. P. UllmanN). Holt, Rinehart \& Winston, New York.

Franklin R. E. and Rynearson E, H. (1960) An evaluation of the effectiveness of diet instruction for the obese. Staff Meet. Mayo Clin. 35, 123-124.

Glucksman M. L., Hirsch J., McCully R. S., Barron B. A. and Knittle J. L. (1968) The response of obese patients to weight reduction: A quantitative evaluation of behavior. Psychosom. Med. 30, 359-373.

Gordon E. S. (1969) The present concept of obesity: Etiological factors and treatment. Med. Times 97, 142-155.

Hamburger W. W. (1951) Emotional aspects of obesity. Med. Clin. N. Am. 35, 483-499.

HANLEY F. W. (1967) The treatment of obesity by individual and group hypnosis. Can. Psychiat. Ass. J. 12, 549-551.

Harris M. B. (1969) Self-directed program for weight control-A pilot study, J. abnorm. Psychol. 74, $263-270$.

Hashim S. A. and Van Itallie T. B. (1965) Studies in normal and obese subjects with a monitored food dispensary device. Ann. N. Y. Acad. Sci. 131, 654-661.

Holland J. G. and Skinner B. F. (1961) The Analysis of Bchavior. McGraw-Hill, New York.

Homme L. E. (1965) Perspectives in psychology: XXIV. Control of coverants, the operants of the mind. Psychol. Rec. 15, 501-511.

KANFER F. H. (1971) Self-monitoring: Methodological limitations and clinical applications. $J$. consult. clin. Psychol. in press.

Kanfer F. H. and Marston A. R. (1963) Conditioning of self-reinforcement responses: An analogue to self-confidence training. Psychol. Rep. 13, 63-70.

Kaplan H. I. and KaplaN H. S. (1957) The psychosomatic concept of obesity. J. nerv. ment. Dis. 125, 181-201.

Konishi F. (1965) Food energy equivalents of various activities. J. Am. Diet. Ass. 46, 186-188.

KORNHABER A. (1968) Group treatment of obesity. G.P. 5, 116-120.

KROGER W. S. (1970) Comprehensive management of obesity. Am. J. clin. Hypnosis 12, 165-176.

MacCuish A. C., Munro J. F. and Duncan L. J. P. (1968) Follow-up study of refractory obesity treated by fasting. Br. Med. J. 1, 91-92. 
MAYer J. (1967) Inactivity, an etiological factor in obesity and heart disease. In Symposia of the Swedis/ Nutrition Foundation, V: Symposium on Nutrition and Physical Activity (Ed. G. Bulx). Almqvist \& Wiksells, Uppsala, Sweden.

MAyer J. (1968) Overweight: Causes, Cost and Control. Prentice-Hall, Englewood Cliffs, N.J.

MeEs H. L. and Keutzer C. S. (1967) Short term group psychotherapy with obese women. NW Med. 66, 548-550.

Metropolttan Insurance Company (1969) New weight standards for men and women. Statisfical Bulletin 40, 1-8.

MEYER V. and CRisp A. H. ( 1964 ) Aversion therapy in two cases of obesity. Behav. Res. \& Therap. 2, 143-147.

MODELL W. (1960) Status and prospect of drugs for overeating. J. Am. Med. Ass. 173, 1131-1136.

Newburgh L. H. and Johnston M. W. (1930) The nature of obesity. J. clin. Invest. 8, 197-213.

NisbetT R. E. (1968) Taste, deprivation, and weight determinants of eating behavior. J. person. soc. Psycho/. 10, $107-116$.

Nisbett R. E. and Kanouse D. E. (1969) Obesity, food deprivation, and supermarket shopping behavior. J. person. soc. Psychol. 12, 289-294.

Penick S. B., Filion R., Fox S. and Stunkard A. (1970) Behavior modification in the treatment of obesity. Paper presented at the annual meeting of the Psychosomatic Society, Washington, D.C.

Powell J. and AzRIN N. (1968) The effects of shock as a punisher for cigarette smoking. J. appl. Behav. Anal. 1, 63-71.

Ramsay R. W. (1968) Vermageringsexperiment, Psychologisch Labratorium van de Universiteit van Amsterdam, Researchpracticum 101, voorjaar 1968.

SCHACHTER S. (1968) Obesity and eating. Science 161, 751-756.

SChaCHTER S., Goldman R. and Gordon A. (1968) Effects of fear, food deprivation, and obesity on eating. J. person. soc. Psychol. 10, 91-97.

Schachter S. and Gross L. P. (1968) Manipulated time and eating behavior. J. person. soc. Psychol. 10, 98-106.

Seltzer C. C. and Mayer J. (1965) A simple criterion of obesity. Postgrad. Med. 38, A 101-Al06.

Shipman W. G. and Plesset M. R. (1963) Anxiety and depression in obese dieters. Archs gen. Psychiat. 8, 26-31.

Silverstone J. T. and Solomon T. (1965) The long-term management of obesity in general practice. Br. J. clin. Pract. 19, 395-398.

SimON R. I. (1963) Obesity as a depressive equivalent. J. Am. Med. Ass. 183, 208-210.

Stanley E. J., Glaser H. H., Levin D. G., Adams P. A. and Cooley I. C. (1970) Overcoming obesity in adolescents: A description of a promising endeavour to improve management. Clin. Pediat. 9, 29-36.

STOKes S. A. (1969) Fasting for obesity. Am. J. Nurs. 69, 796-799.

STUART R. B. (1967) Behavioral control of overeating. Behav. Res. \& Therapy 5, 357-365.

StUART R. B. (1971) Situational versus self control. In Advances in Behavior Therapy (Ed. R. D. RUBIN). Academic Press, New York, in press.

Stuart R. B. and Davis B. (1971) Behavioral Techniques for the Management of Obesity. Research Press. Champaign, Ill., in press.

Stunkard A. (1959a) Eating patterns and obesity. Psychiat. Q. 33, 284-295.

Stunkard A. (1959b) Obesity and the denial of hunger. Psychosom. Med. 21, 281-289.

STUNKARD A. (1968) Environment and obesity: Recent advances in our understanding of regulation of food intake in man. Fed. Proc. 6, 1367-1373.

Stunkard A., LeVINe H. and Fox S. (1970) The management of obesity. Archs intern. Med. 125, $1067-1072$.

Stunkard A. and MCLAREN-Hume M. (1959) The results of treatment for obesity. Archs intern. Med. 103, 79-85.

Suczex R. F. (1957) The personality of obese women. Am. J. Clin. Nutr. 5, 197-202.

United States Public Health Service (undated) Obesity and Health. (Publication No. 1495), United States Department of Health, Education and Welfare, Washington, D.C.

United States Senate, Select Committee on Nutrition and Human Needs (1970) Nutrition and Human Needs-1970. Parts I, II \& III. U.S. Government Printing Office, Washington, D.C.

WAGonfield S. and Wolowitz H. M. (1968) Obesity and self-help group: A look at TOPS. Am. $J$. Psychiat. 125, 253-255.

WANG R. I. H. and SANDOVAL R. (1969) Current status of drug therapy in management of obesity. Wis. Med. J. 68, 219-220.

YUDKIN J. (Spring, 1969) Sucrose and heart disease. Nutrition Today 4, 16-20. 